\title{
National Travel Assistance Entitlements Are Inaccessible to Whānau Māori
}

\author{
Bridgette Masters-Awatere, \\ Sarah Murphy, Toni Bailey Helmhout, \\ and Kahurimu Flavell \\ University of Waikato
}

\author{
Donna Cormack \\ University of Auckland
}

New Zealand's National Travel Assistance scheme is intended to provide financial support for people who need to either travel frequently or over long distances for specialist health care treatment. Taking an Indigenous Psychology orientation to "away-from-home" hospital admissions, we broaden the focus beyond an individual's physical experience of hospitalization to the wider social and political context. Based on our research, we recommend a whanau-centered approach to travel assistance that will offer better coordination and remove factors negatively impacting whānau Māori (Indigenous families in New Zealand) health outcomes and contribute to United Nations Sustainable Development Goal 10 of reducing inequality. Our research is congruent with the community psychology value of "accountability" and the World Health Organisation value of "better health for everyone, everywhere."

\begin{abstract}
Impact and Implications
Maori cultural values place importance on being with a loved one during their time of illness. The National Travel Assistance (NTA) scheme is intended to ease the financial burden of long-distance travel for specialist health care. Our interviews highlight that while well-intentioned, systematic barriers make access to NTA support hard for whānau Māori. A broader transformation to the health system will likely reduce the stressors that make the NTA necessary for whānau Māori in the first place. Our argument for a whānau-centered approach to reduce health inequalities during an away-from-home hospital admission is congruent with Sustainable Development Goal 10.
\end{abstract}

Keywords: community psychology, treaty rights, hospital transfers, Māori health

Hospital admissions can be stressful for patients and their whānau (family). When an admission involves a transfer away from a person's home hospital, there are additional issues for whānau in negotiating distance, unfamiliar environments, and maintaining active
Bridgette Masters-Awatere, Maori and Psychology Research Unit, School of Psychology, University of Waikato; Sarah Murphy, Toni Bailey Helmhout, and Kahurimu Flavell, School of Psychology, University of Waikato; Donna Cormack, Te Kupenga Hauora Maori, University of Auckland.

The research project from which this paper was derived received funding from Ngā Pae o te Māramatanga - New
Zealand's Māori Centre of Research Excellence. The project entitled "Hospital Transfers" was funded November 2016-March 2019 (ref:NPM 16RF14).

Correspondence concerning this article should be addressed to Bridgette Masters-Awatere, Maori and Psychology Research Unit, School of Psychology, University of Waikato, Private Bag 3105, Hamilton 3240, New Zealand.

E-mail: Bridgette.Masters-Awatere@waikato.ac.nz 
engagement in decision-making. The larger "Hospital Transfers" project that informed this article brought together researchers, whānau, hospital-based medical practitioners, and Māori (Indigenous peoples of New Zealand) service providers to find ways to answer the question: How can whānau maintain active engagement in caring for their whānau member when they need hospital care away from their home base? ${ }^{1}$

Before the arrival of colonizers in New Zealand, Māori had traditional health structures and systems that had been developed over many generations. Systems that were tailored to the environment and the people who lived within (Ratima, 2001) reflected our holistic and collective concepts of health. Colonization fundamentally disrupted these systems, with newly imposed legislation (Durie, 1997) and health systems, including hospitals, configured primarily to serve Pākehā (Waitangi Tribunal, 2001). ${ }^{2}$ The resulting current public health system reflects models of care that starkly contrast with Māori concepts of health. Persistent health inequities exist in health care and health status (Ministry of Health, 2015). Māori hospital admissions are higher than those of non-Māori, including Māori hospital admissions that are considered potentially avoidable through earlier intervention (Ministry of Health, 2015). Inequitable health system outcomes experienced by Māori demonstrate the government's failure to meet their obligations and responsibilities to Māori as outlined in te Tiriti o Waitangi (Reid \& Robson, 2007). ${ }^{3}$

Ongoing Te Tiriti breaches have systematically impacted Māori communities politically and socially and are an underpinning driver of inequities in Māori health and well-being. Māori also report experiencing racism, including in health care (Ministry of Health, 2015). Such experiences are barriers to further engagement and known contributors to lesser health outcomes-accessing treatment and ongoing care as well as early discharge from hospital (Graham \& Masters-Awatere, 2020). Māori are a significant proportion of health service users, and it is imperative that the system is culturally safe and supports the overall healing process for patients and wider whānau. One way this can happen is by ensuring better access to National Travel Assistance (NTA) for whānau Māori when they need to travel for hospital care.
The key national level policy, established in 2005, instrumental for supporting whānau engagement in hospital care is the Ministry of Health's NTA Scheme. Intended to assist with costs when receiving specialist treatment, the process generally requires whānau to carry costs upfront and then seek reimbursement afterward. If eligible, patients and whānau must lodge claims for reimbursement within 12 months of the hospital admission. Payments are then given retrospectively to whānau for mileage and accommodation costs. Absent from consideration are costs borne relating to time off work, pursuing information regarding entitlements, seeking approvals through various clinical processes, or researching multiple accommodation venues.

\section{Method}

The larger Hospital Transfers project was registered with the Waikato District Health Board, and ethical approval was given by the Human Research Ethics Committee (Health) at the University of Waikato. Three key research activities were undertaken: (a) Kaupapa Māori environmental scan of policies and documentation sourced from publicly available information; (b) review of routinely collected data regarding Māori hospitalizations; and (c) Waikato District Health Board (DHB)-focused study that collected narrative accounts of Māori whānau $(n=22)$, clinical staff $(n=11)$, and transfer personnel $(n=4)$. Although all three activities have informed our thinking, this policy brief draws primarily on our analysis of information sourced from the narrative interviews (Research Activity 3 ) and builds on our submission to the NTA Policy Review Committee (MastersAwatere, Cormack, Brown, Rata, \& Boulton, 2018).

Forty-six interviews were undertaken with a range of people who had transfer experiences with Waikato Hospital. Snowball sampling using a peer referral system resulted in 22 inter-

\footnotetext{
${ }^{1}$ Mari are the Indigenous people of New Zealand; whanau Maori are family members who provide support.

${ }^{2}$ Pakeha is the Maori word that refers to New Zealand citizens of primarily European descent.

${ }^{3}$ Referred to as New Zealand's founding document; Te Tiriti or te Tiriti o Waitangi refer to the version written in te reo Marori [Indigenous language].
} 
views with whānau Māori who were transfer patients and/or support people. All whānau were involved in a transfer from their local hospital to Waikato Hospital for a minimum of a one-night stay during the 12 -month period before being interviewed. ${ }^{4}$ Whānau participant ages ranged from 19 to 84 years. Eleven clinical staff at Waikato Hospital discussed their observations and experiences regarding transfers. Their length of time as employees in the hospital ranged from 5 to 20 years. Four transfer personnel whose roles involved oversight or planning of transfer patients to Waikato Hospital were also interviewed. The key informants were interviewed in clusters - whānau (MarchJune 2017), clinical staff (February-May, 2018), and transfer personnel (SeptemberNovember 2018).

\section{Findings}

When we interviewed whānau, less than 12 months had passed since the hospital transfer experience; many still were unclear if they were entitled to travel assistance support. Furthermore, those who knew of NTA commented on a lack of clarity about what was covered or not (for more details, see Masters-Awatere et al., 2019). Whānau identified a range of contributors as stressors for them (such as reimbursement rather than upfront support, low rate of reimbursement [mileage and distance], high daily charges for hospital parking, and accommodation support not recognizing peak seasons and increased costs associated with staying in a major center).

Whānau access to information about NTA often relied on hospital staff communicating their knowledge. The language of the policy could present difficulty, as it did not necessarily follow a logic that centered how whānau needed the information. Sadly, whānau conveyed ways that experiences with hospital staff were understood as a sense of reluctance to assist with access to NTA support. In addition, variations such as changes in circumstances, and increased frequency of hospital visitations, potentially affected eligibility. Negative interactions that impacted the willingness of whannau to seek clinical "sign-off" (approval) were barriers to those who already felt vulnerable within the hospital's hierarchical environment.
Complementary with whānau narratives about access to information were those of clinical staff and transfer personnel. Inconsistent delivery of health information to whānau, which included information about access to NTA entitlements, was specifically mentioned. A common cause of frustration for all three participant groups was miscommunication. Miscommunication within the same hospital (intratransfer) and between hospitals (intertransfer) was reported as common with regards to NTA. One example of a common misunderstanding was that District Health Boards funded NTA. ${ }^{5,6}$ NTA reimbursements are funded by the Ministry of Health (Ministry of Health, 2019).

\section{Policy Implications and Recommendations}

The Ministry of Health is committed to the World Health Organisation (WHO) aspiration through ensuring its policies and processes contribute to better health for everyone, everywhere. Subsequently the NTA policy is intended to serve everyone in need. When considered in combination with the United Nations Sustainable Development Goal 10 of reducing inequality, the Ministry of Health's obligation as a government agency means the provision of accessible services to whānau Māori is implicit.

In 2018, the Ministry of Health formed an NTA policy review committee and called for submissions. Our team made an oral submission that was based on our written submission (Masters-Awatere et al., 2018). Within both submissions, we advocated for a whānau-centered approach. The following is an abridged version of our recommendations to the NTA policy review committee, with specific notation of relevance to SDG 10 reducing inequality, the community psychology value of "accountability," and the

\footnotetext{
${ }^{4}$ Publicly-funded hospital based in Hamilton servicing a population of over 420,000 in a region that covers Coromandel in the north down to near Mount Ruapehu in the south.

${ }^{5}$ There are 20 DHBs in New Zealand. Waikato DHB has a large geographical catchment area and a tertiary hospital located in Hamilton City. https://www.health.govt.nz/ system/files/documents/pages/waikato.pdf.

${ }^{6}$ NTA is a national policy set by the Ministry of Health administered at the individual DHB level. The NTA scheme underwent a review in 2018. It continues to be administered by DHBs.
} 
WHO value of "better health for everyone, everywhere."

Currently only certain specialists have been delegated the authority to approve NTA applications from within DHBs. An assumption is that specialists know and have at their fingertips the details of the NTA policy, the criteria for accessing support, the correct paperwork required, and details of who can assist whānau should they need ongoing help. Furthermore, a specialist's approval requires a relationship with whānau that (a) involves interactions that last long enough for whānau to feel comfortable enough to ask for the signature and (b) have been positive so as not to diminish the mana [dignity] of whānau. An example of a poor relationship that is both humiliating and stigmatizing is one where whānau are asked to "prove" their low-income status (through immediate presentation of a community services card). ${ }^{7}$

The current process maintains a power imbalance in the hospital environment whereby access to the NTA policy is dependent upon the specialist. To enhance whānau rangatiratanga (authority), a whānau-centered approach to resourcing whānau through administration of the NTA means implementing the policy in a more socially just manner. One that shifts accountability for delivering support from the specialist and holds them accountable for ensuring the well-being of the whole whannau is maintained through access to appropriate medical and social services. If funding to hospitals was dependent on ensuring whānau needs were met, we envisage a reduction of inconsistencies regarding NTA knowledge from staff within and between DHBs.

The cultural practice of "never leaving a patient alone" began before the arrival of Pākehā and has evolved as a result of intergenerational racist and stigmatizing experiences with health system staff-through primary, secondary and tertiary care (Reid \& Robson, 2007). Such negative experiences have contributed to negative perceptions of the health system by Māori whānau (Graham \& Masters-Awatere, 2020). The cost burden upon whānau to maintain their cultural practice and beliefs is carried more heavily upon their shoulders (through time off work, travel and accommodation costs, research and inquiry regarding NTA) while maintaining vigilant support by their loved one's side. Māori can have poorer health requiring longer hospi- talization as a result of presenting with coexisting conditions that result from inequitable access to the social determinants of health. Modifying implementation of the NTA to be more reflexive of Māori lives would go a long way to reducing inequality on multiple levels.

\section{Closing Comments}

Although some of our recommendations have been reflected in the NTA review (Ministry of Health, 2019), our team believes the health system requires a broader transformation to reduce the stressors that make the NTA more necessary for whānau Māori in the first place. A redistribution of resources and investment to develop and deliver truly whānau-centered hospital care would change the health landscape. An example would be having specialists travel to regional hospitals to provide care (reducing the frequent need for whānau to travel away from their home, support structures, and potentially shorten the length of stay in a hospital away from their home when one is needed). Our recommendations to implement a whānaucentered approach are a step in the right direction toward strengthening the Ministry of Health's delivery of an NTA scheme that would ensure entitlements are accessible to whānau Māori-thus meeting Te Tiriti o Waitangi Article III obligations of equal rights to access. Furthermore, an observed reduction in inequality (Sustainable Development Goal 10) would be consistent with the community psychology values of social justice and accountability while simultaneously contributing to the WHO's value of "better health for everyone, everywhere."

\footnotetext{
${ }^{7}$ A community services card is intended to help individuals and their families with the costs of health care. It entitles the holder and their family to a reduction in the cost of some health services and prescriptions. The time between application and receipt of a card can take several weeks and requires evidence of need.
}

\section{References}

Durie, M. (1997). Identity, nationhood and implications for practice in New Zealand. New Zealand Journal of Psychology, 26, 32-38.

Graham, R., \& Masters-Awatere, B. (2020). Experiences of Māori of Aotearoa New Zealand's public 
health system: A systematic review of two decades of published qualitative research. Australian and New Zealand Journal of Public Health, 44, 193 200. http://dx.doi.org/10.1111/1753-6405.12971

Masters-Awatere, B., Cormack, D., Brown, R., Boulton, A., Tangitu-Joseph, M., \& Rata, A. (2019). Hospital Transfers: Supporting whānau engagement during hospitalisations (Te Arotahi Series \#4). Auckland, New Zealand: Ngā Pae o te Māramatanga, University of Auckland. Retrieved from http:// ebooks.auckland.ac.nz/tearotahi_december_2019_ no_4/

Masters-Awatere, B., Cormack, D., Brown, R., Rata, A., \& Boulton, A. (2018). Hospital transfers: Maintaining active whānau engagement. Submission to the National Travel Assistance Policy Review Committee, Ministry of Health Wellington. Hamilton, New Zealand: Māori \& Psychology Research Unit.

Ministry of Health. (2015). Tatau Kahukura: Māori health chartbook (3rd ed.). Wellington, New Zealand: Author.
Ministry of Health. (2019). The national travel assistance scheme: Policy recommendations report. Wellington, New Zealand: Author. Retrieved from https://www.health.govt.nz/publication/nationaltravel-assistance-scheme-policy-recommendations-report

Ratima, M. (2001). Kia uruuru mai a hauora [Being healthy, being Māori] Conceptualising Māori health promotion (Doctoral thesis). University of Otago, Dunedin, New Zealand.

Reid, P., \& Robson, B. (2007). Understanding health inequalities. In B. Robson \& R. Harris (Eds.), Hauora: Maori standards of health IV. A study of the years 2000-2005 (pp. 3-10). Wellington, New Zealand: Te Rōpū Rangahau Hauora a Eru Pomare.

Waitangi Tribunal. (2001). The Napier Hospital and health services report: WAI 692. Wellington, New Zealand: Author.

Received July 21, 2019

Revision received May 27, 2020

Accepted May 30, 2020 